\title{
The effectiveness of pregnant women with type 1 diabetes mellitus management with continuous subcutaneous insulin infusion
}

\author{
T.Mokhort ${ }^{1}$, T.Skryplionak ${ }^{2}$ \\ 1- Belarusian State Medical University, Minsk, Belarus \\ 2. «Mother and Child» national research center, Minsk, Belarus, email:tnskrip@yandex.ru
}

Aim: assess the effectiveness of management of pregnant women with type 1 diabetes mellitus (DM 1) with continuous subcutaneous insulin infusion (CSII)

Materials and Methods: Pregnant women with DM 1 with CSII $(n=21)$ - the main group and on multiple daily insulin injections $(M D I)(n=216)$ - the comparison group. We used different models of the Medtronic pumps. The inclusion in the comparison group carried out by a continuous method. The term of delivery, the frequency of preeclampsia, the level of glycated hemoglobin (HbA1c) in the 3rd trimester were used as efficiency criteria.

Results: In the main group, premature delivery was only $9,5 \%$, compared with $53,7 \%$ in the group of MDI . The incidence of preeclampsia in the main group was significantly lower and amounted to $19,1 \%$, compared with $52,8 \%$ in the comparison group. Also, the level of HbA1c in the third trimester in the main group were significantly less than in the comparison group and amounted to $5,92 \%$, in comparison with $6,73 \%$.

\begin{tabular}{|c|c|c|}
\hline & CSII & MDI \\
\hline Preterm delivery n, \% & $2(9,5 \%)$ & $116(53,7 \%)^{*}$ \\
\hline Preeclampsia n, \% & $4(19,1 \%)$ & $114(52,8 \%)^{*}$ \\
\hline $\begin{array}{c}\text { The average HbA1c in } \\
\text { the 3rd tr.,\% }\end{array}$ & $5,92 \%$ & $6,73 \%{ }^{*}$ \\
\hline
\end{tabular}

$\left({ }^{*}\right.$ - the difference were significant, $\left.p<0,05\right)$

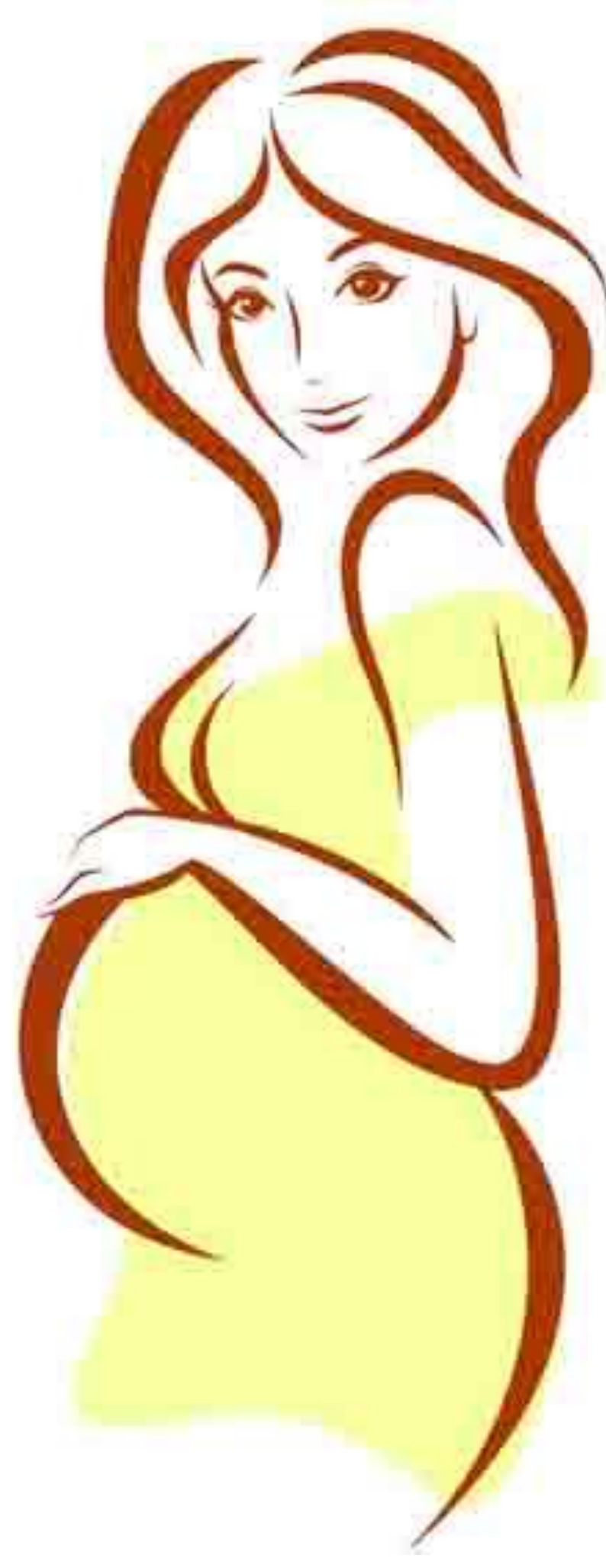

CSII - continuous subcutaneous insulin infusion, MDI - multiple daily insulin injections

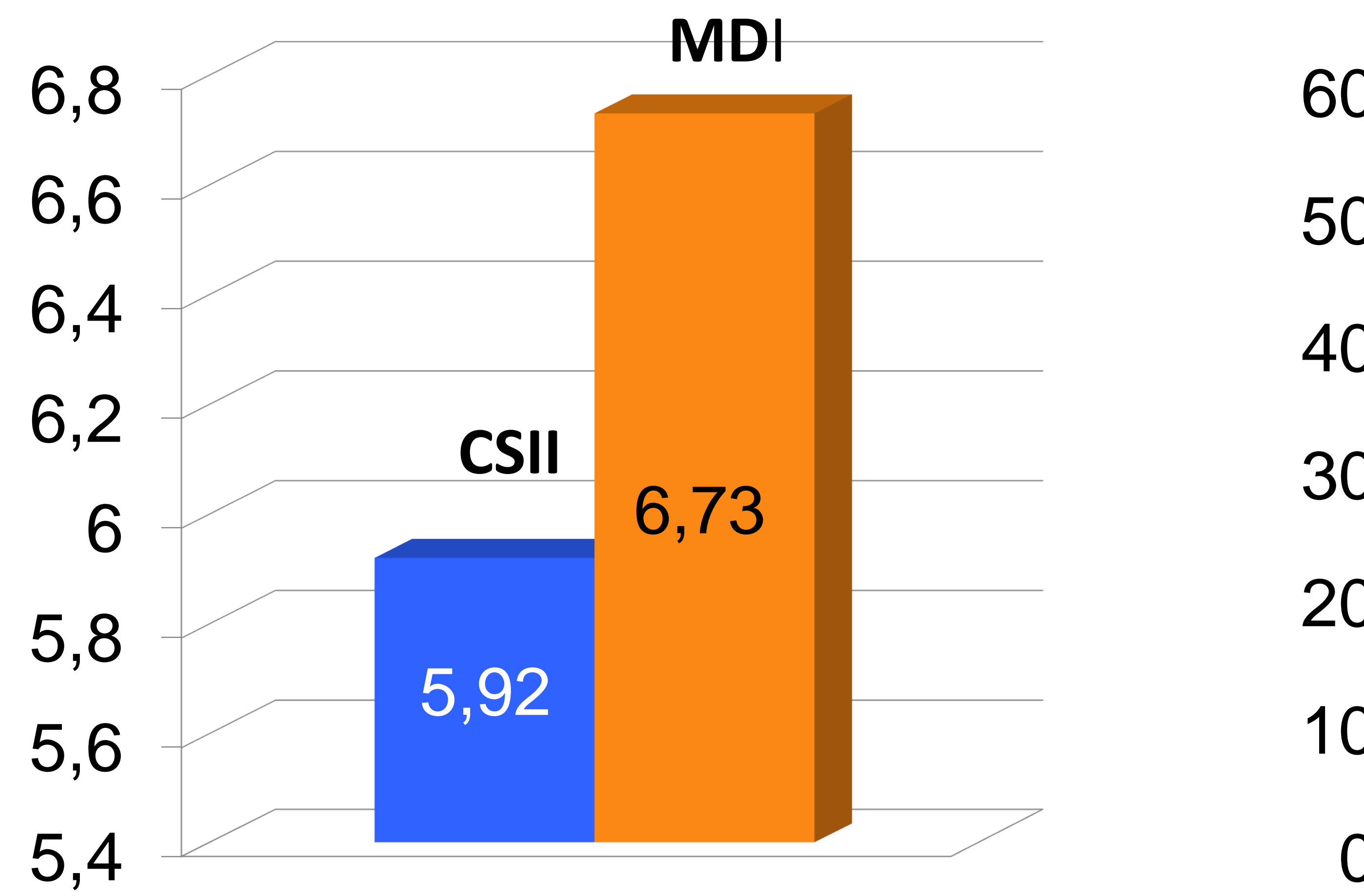

The average HbA1c in the 3rd tr.,\%

60
50
40
30
20
10
0

0

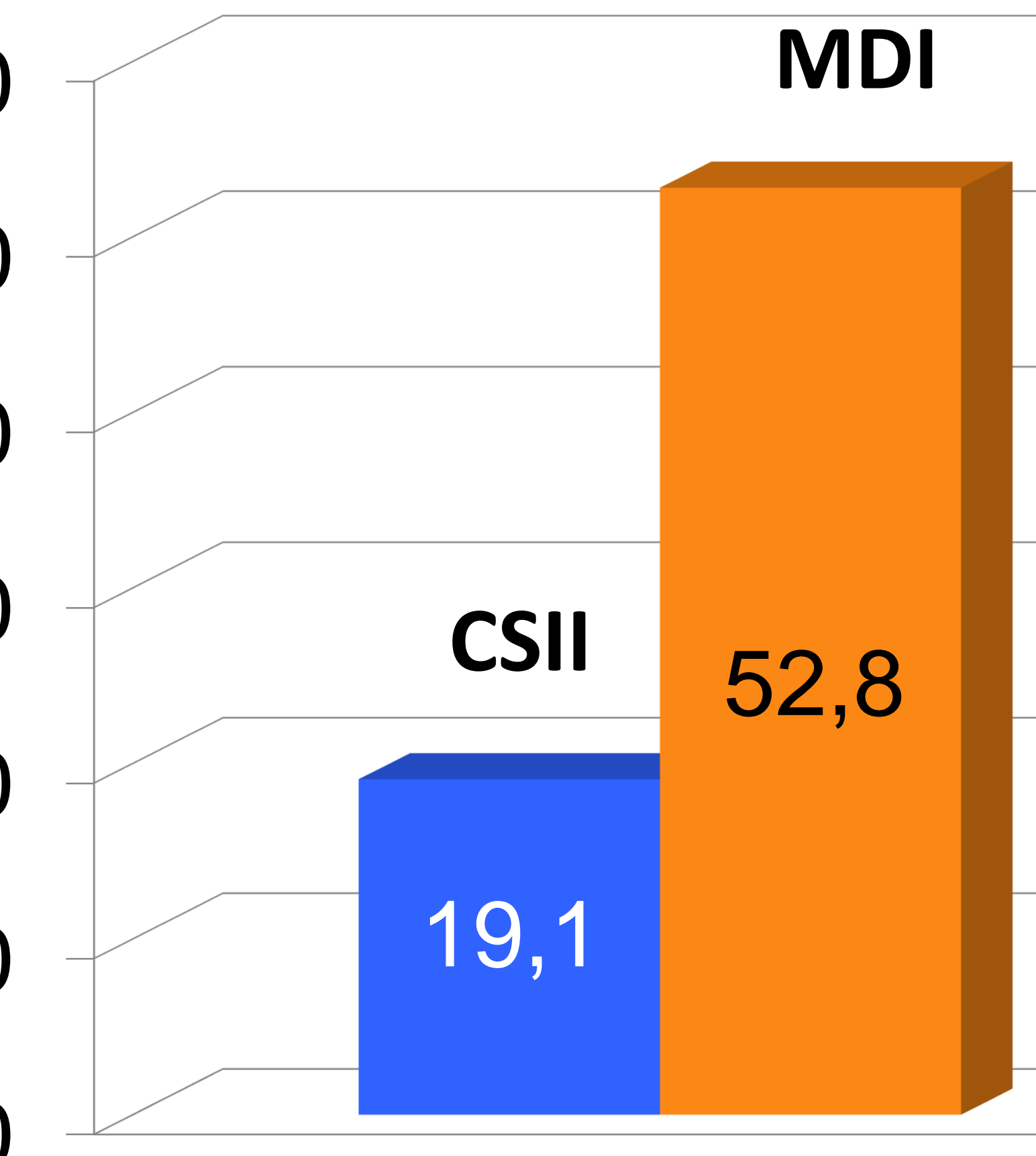

Preeclampsia,\%

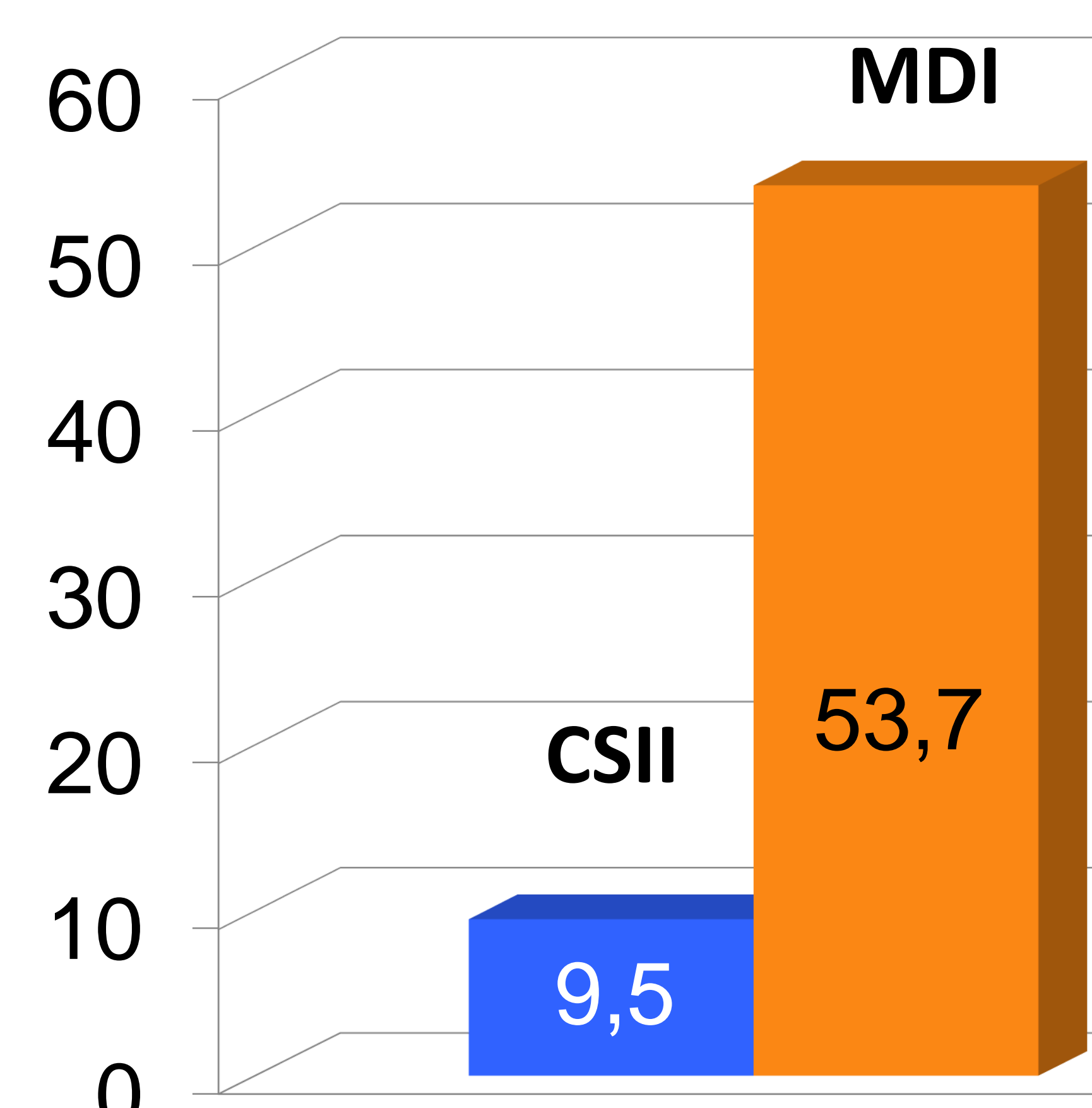

Preterm delivery, \%

Conclusions: The continuous subcutaneous insulin infusion is an effective method of management of pregnant women with type 1 diabetes, which allows obtaining a full-term child in $90 \%$ of cases against the background of the optimal state of carbohydrate metabolism, reducing the frequency of preeclampsia. 